\section{NERO TRIBUTE}

It was with great interest that I read he tribute in the recent Blue Jay hanking Bob Nero for his many conributions to the Saskatchewan Natural History Society on the occaion of his resignation from the ditorial staff of the Blue Jay.

While I echo the sentiments exressed in the article, I feel it missed ommenting on one of his most imortant contributions to the fostering $f$ natural history in the prairie egion, a contribution that affected he directly. I refer to the support and ncouragement that Bob has conistently given to young people who ad a strong interest in natural istory, but who required a certain egree of help and direction. Bob was ever too busy to talk to, or corresond with, such "high-school aturalists" and provided many of hem with employment and practical xperience in ornithology. As a direct onsequence of Bob's enthusiasm, a umber of these people are currently ursuing careers in biology or other Ich areas of natural history, many of hem on the prairies. - M. Ross Lein, sst. Professor of Biology, The niversity of Calgary, Calgary, Iberta T2N 1N4

\section{VENING GROSBEAKS}

We are greatly impressed with the lue lay and enjoy reading the varied ticles. Being an amateur bird atcher of many years, I find the bird hotographs and information esccially interesting.

We have had a large flock of Eveng Grosbeaks here since January 19 , eding on the sunflower heads in the ick garden and a head tied to a pole the front yard. In less than two onths they have eaten 50 lbs. of urchased sunflower seeds from the vo feeders set up. They have ecome quite tame; we can go in and It of the back door quietly and not sturb them feeding 15 feet away at e feeder. When the feeder is empty ey are quite vocal in their protests!

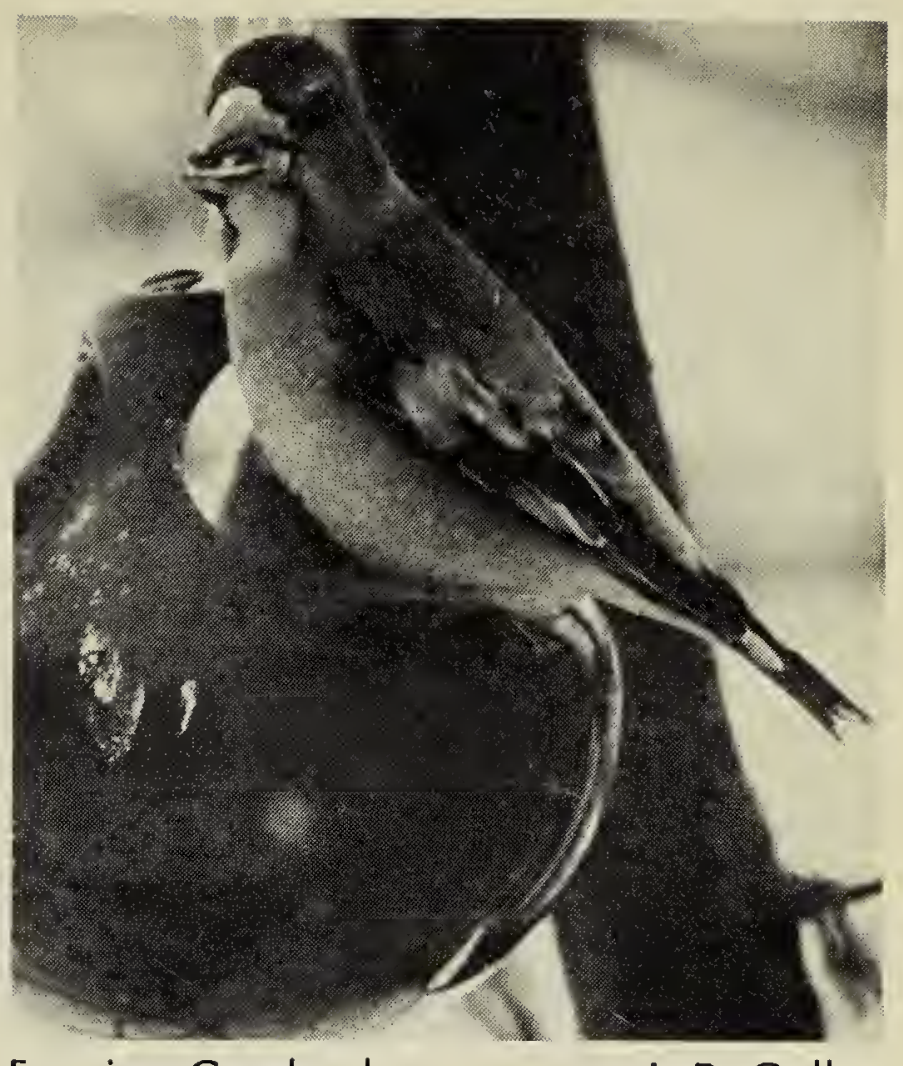

Evening Grosbeak

J. B. Gollop

A pair of Downy Woodpeckers and a pair of chickadees have eaten suet tied to the feeder poles from January till now (March 23). The woodpeckers will feed while the grosbeaks feed at the feeders but the chickadees are not as bold; they wait until they leave.

Evening Grosbeaks have never stayed around more than two or three days before. They used to come, stay a day or so and then leave; but with ready food so available, this must be the reason for their stay. There are several other feeding places in town now for them, and they are giving a lot of enjoyment to all. - Mrs. Arley Nickel, Box 84, Laird, Saskatchewan SOK $2 \mathrm{HO}$

NOTE: re: A. Didiuk's article "Whooping Cranes in Manitoba", condensed from Manitoba Nature (Blue Jay 34:234-236), the author is prepared to modify his statement about Whooping Cranes nesting outside the park to say that, although the possibility exists, those breeding in areas presently unknown are not contributing to the population. 


\section{PRAIRIE CHICKENS IN THE 1920's}

In the week of March 1, 1977, I visited a friend in Toledo, Ohio, on the extreme west part of Lake Erie. While there I met Lee Herzberger from a nearby National Wildlife Refuge. For two years Lee had been in charge of the Greater Prairie Chicken or Pinnated Grouse project in Texas. They were on the endangered list but lately have increased to the point where they are not so considered. I was very interested because the Greater Prairie Chicken was quite common when I first came to Canada in 1919. At sunrise on a calm April or May morning I would hear their boom, boom noise on the dancing ground. By 1928 they had disappeared from our area which is about 15 miles north of the Moose Mountains.

In the Blue Jay there have been occasional reports of them. It would give me great pleasure to hear of breeding stock still in Saskatchewan. - G. M. Hewson, Langbank, Saskatchewan.

\section{HIGH FLYING SNOWY OWL}

I am not sure if it is generall: known that Snowy Owls may migrat at a great height. Usually they ar seen perched on a telephone pole on the ground or flying low.

On March 20, 1977, at approximate ly 1100 I noticed the Canada Geese o Wascana Lake in Regina, looking a something in the sky. I looked an looked and with some difficulty final ly saw a white speck high up an almost directly overhead. With th aid of $7 X$ binoculars, I could see it wa a Snowy Owl.

It was soaring or gliding in grea sweeping circles when first seen, bi then it flew in a northeasterly dires tion, alternately gliding and flappin as it went. - Fred W. Lahrma! Saskatchewan Museum of Natur History, Regina.

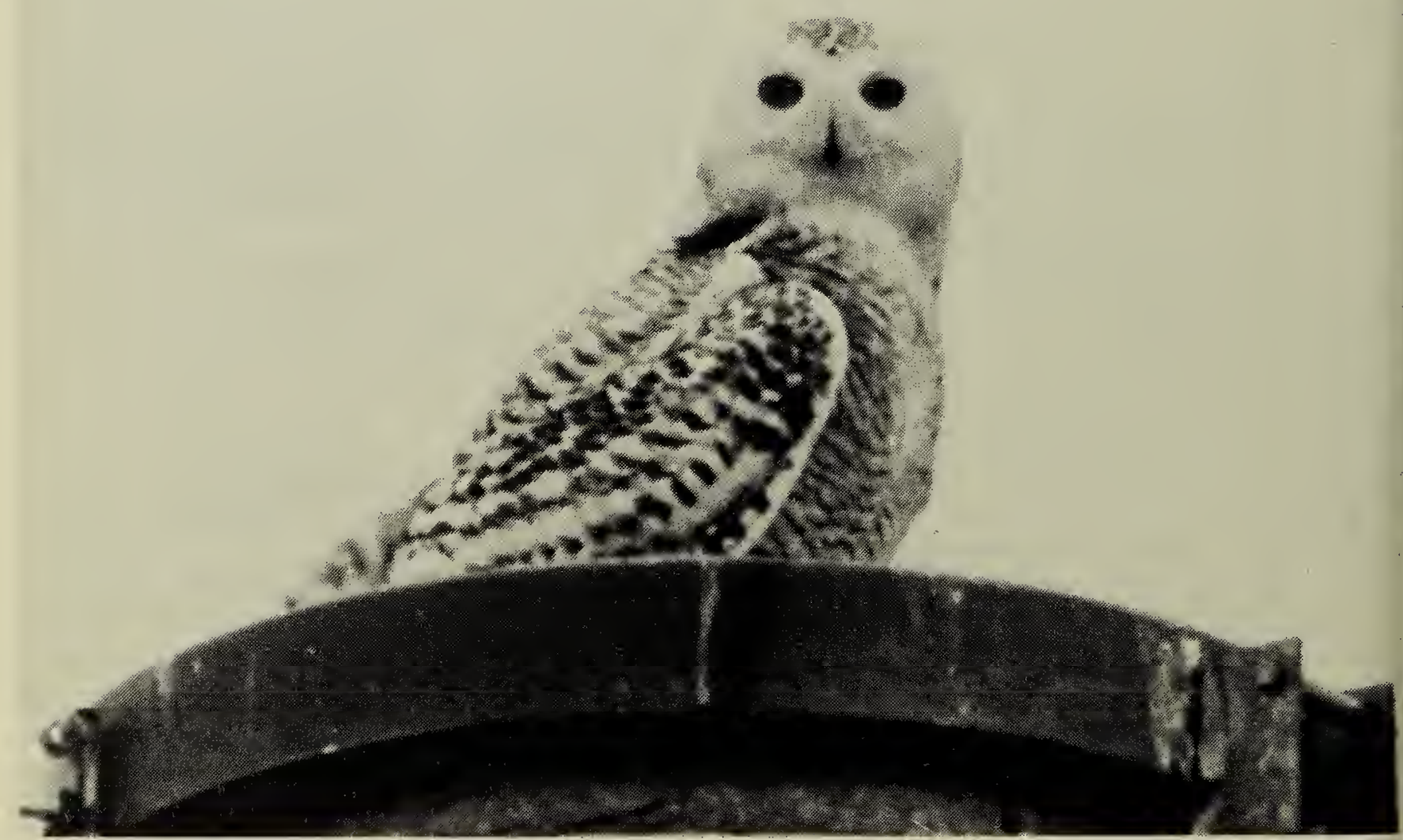

